\title{
Ortaokul Öğretmenlerinin TIMSS Sınavına İlişkin Görüşlerinin İncelenmesi
}

\author{
Hasan Özcan ${ }^{1}$, Hakkı İlker Koştur ${ }^{2}$ \\ ${ }^{1}$ Matematik ve Fen Bilimleri Eğitimi Bölümü, Eğitim Fakültesi, Aksaray Üniversitesi, Aksaray, Türkiye \\ ${ }^{2}$ Temel Eğitim Bölümü, Eğitim Fakültesi, Başkent Üniversitesi, Ankara, Türkiye
}

Sorumlu Yazar: Hasan Özcan, hozcan@aksaray.edu.tr

Makale Türü: Araştırma Makalesi

Kaynak Gösterimi: Özcan, H., \& Koştur, H. İ. (2019). Ortaokul öğretmenlerinin TIMSS Sınavına ilişkin görüşlerinin incelenmesi. Eğitimde Kuram ve Uygulama, 15(2), 108-120. doi: 10.17244/eku.545291

\section{Examining Middle School Teachers' Views about TIMSS}

$$
\text { Hasan Özcan }{ }^{1} \text {, Hakkı İlker Koştur² }
$$

${ }^{1}$ Department of Mathematics and Science Education, Faculty of Education, Aksaray University, Aksaray, Turkey ${ }^{2}$ Department of Elemantary Education, Faculty of Education, Başkent University, Ankara, Turkey

Corresponding Author: Hasan Özcan, hozcan@aksaray.edu.tr

Article Type: Research Article

To Cite This Article: Özcan, H., \& Koştur, H. İ. (2019). Ortaokul öğretmenlerinin TIMSS Sınavına ilişkin görüşlerinin incelenmesi. Ĕgitimde Kuram ve Uygulama, 15(2), 108-120. doi: 10.17244/eku.545291 


\title{
Ortaokul Öğretmenlerinin TIMSS Sınavına İlişkin Görüşlerinin İncelenmesi
}

\author{
Hasan Özcan ${ }^{1}$, Hakkı İlker Koştur ${ }^{2}$ \\ ${ }^{1}$ Matematik ve Fen Bilimleri Eğitimi Bölümü, Eğitim Fakültesi, Aksaray Üniversitesi, Aksaray, Türkiye \\ ORCID: https://orcid.org/0000-0002-4210-7733 \\ ${ }^{2}$ Temel Ĕ̆itim Bölümü, Ĕgitim Fakültesi, Başkent Üniversitesi, Ankara, Türkiye \\ ORCID: https://orcid.org/0000-0001-8557-4385
}

\begin{abstract}
Öz
Bu çalışmanın amacı öğretmenlerin Uluslararası Matematik ve Fen Eğilimleri Araştırması (TIMSS - Trends in International Mathematics and Science Study) sinavi hakkındaki görüşlerini incelemektir. TIMSS sınavının paydaşı konumunda olan öğretmenlerin bu sınav hakkındaki bilgileri, düşünceleri, Türkiye'nin bu sınav sonuçlarına göre dünya sıralamasındaki yeri, sınavın içeriği, sınavda hangi alanlardan soruların sorulduğu, soruların nelerri ölçtüğü ve TIMSS sınavında Türkiye'nin başarılı olması için sundukları önerileri ve görüşleri önemlidir. Öğretmenlerden birçok ülkede uygulanan ve ülkelerin fen ve matematik başarılarına göre sıralandığı TIMSS sınavı hakkında bilgi sahibi olmaları beklenmektedir. Bu amaçla Aksaray ilinde bulunan iki farklı ortaokulda görev yapan 15 öğretmenle yarı yapılandırılmış görüşmeler yapılmıştır. Bu görüşmelerde katılımcıların demografik bilgi formunu doldurması sağlanmış ve açık uçlu sorulardan oluşan TIMSS Testi Görüşme Formu uygulanmıştır. Öğretmenlerin görüşleri incelendiğinde TIMSS sınavına dair bilgilerinin genel anlamda yeterli olduğunu sonucuna ulaşılmıştır. Ayrıca çalışmada TIMSS sınavında ülkemizin başarısının artırılması konusunda öğretmenlerin sunduğu önerilere yer verilmiştir.
\end{abstract}

Makale Bilgisi

Anahtar Kelimeler: TIMSS, Uluslararası matematik ve fen eğilimleri araştırması, Ortaokul öğretmenleri, Öğretmen görüşleri

\section{Makale Geçmişi:}

Geliş: 31 Ocak 2018

Düzeltme: 06 Mart 2019

Kabul: 09 Mart 2019

Makale Türü: Araştırma Makalesi

\section{Examining Middle School Teachers' Views about TIMSS}

\begin{abstract}
The purpose of this study was to investigate teachers' opinions about Trends in International Mathematics and Science Study (TIMSS) exam. Teachers are indirectly stakeholders of the TIMSS exam and, their knowledge and opinions about the exam, their predictions about the ranking of Turkey in the world, their knowledge about the content and topics, what kind of knowledge and skills exam questions measure, their suggestions and opinions about improving the success of Turkey in the exam are important. Teachers are expected to have knowledge about the TIMSS exam which is applied in many countries, and countries are ranked according to their science and mathematics achievements. For this purpose, semi-structured interviews were conducted with 15 teachers working in two different secondary schools in Aksaray province. In these interviews, the participants completed the demographic information form and the TIMSS Test Interview Form consisting open-ended questions. When the opinions of the teachers are examined, it is concluded that the information about the TIMSS exam is sufficient in general. In addition, the suggestions of the teachers about increasing the success of our country the TIMSS exam are presented.
\end{abstract}

\section{Article Info}

Keywords: TIMSS, Trends in international mathematics and science study, Middle school teachers, Teachers' opinion

\section{Article History:}

Received: 31 Ocak 2019

Revised: 06 March 2019

Accepted: 09 March 2019

Article Type: Research Article 


\section{Giriş}

Uluslararası Matematik ve Fen Eğilimleri Araştırması (TIMSS - Trends in International Mathematics and Science Study), Hollanda merkezli bir kurum olan Uluslararası Eğitim Başarılarını Değerlendirme Kuruluşu (IEAInternational Association for the Evaluation of Educational Assessment) tarafindan yürütülen ve dört yılda bir uygulanan uluslararası bir sınavdır. TIMSS sınavının amacı, sınava katılan ülkelerden 4. ve 8. sınıf öğrencilerinin seçilmesinin ardından öğrencilerin bilgi ve becerilerinin ölçülmesidir (TIMSS, 2018a). Yapılan her TIMSS sınavında sınava katılan okullar ve sınıflar ülke genelini temsil edecek şekilde rastgele seçilmektedir (Gönen, Özgürlük, Parlak, Polat \& Yıldırım, 2016). TIMSS araştırmasında amaç, TIMSS'e katılan öğrencilerin fen ve matematik başarılarını ölçmenin yanısıra okullarda uygulanan müfredat ne kadar etkili olduğu ve öğretimin nasıl gerçekleştiği gibi sorulara cevap bulmak için bunlar hakkında veriler toplayarak araştırma sonucunda elde edilen bulguları diğer ülkelerin sonuçlarıyla karşılaştırmaktır (Şişman, Acat, Apay \& Karadă̆, 2011). TIMSS sınavı, bir önceki sınava göre öğrencilerin başarı durumlarının karşılaştırılması, başarılı olan ülkelerin başarılı olmasındaki etmenlerin ne olduğu, ülkelerin eğitim politikalarında ve eğitim sisteminde ne gibi değişiklikler olduğu gibi birçok konuda ülkeler arası karşılaştırmalar yapılmasına ve ülkelerin eğitimle ilgili sorunlarına çözüm üretilmesinde yardımcı olmaktadır (Yılmaz, Koparan \& Hanc1, 2016).

İlk TIMSS sınavı 1995 yılında 42 ülkenin katılımı ile gerçekleştirilmiş olup Türkiye bu sınava ilk defa 1999 yılında katılmıştır. Bu sınav, "Üçüncü Uluslararası Matematik ve Fen Çalısması - Tekrar (TIMSS-R)" olarak adlandırılmıştır (TIMSS, 2018b). TIMSS sınavının üçüncüsü 2003 yılında yapılmıştır. Türkiye 2003 yılında gerçekleştirilen bu TIMSS sınavına katılmamış, ancak 2007, 2011 ve 2015 sınavlarına katılmıştır (TIMSS, 2018a).

Ülkemizde TIMSS ile ilgili literatür incelendiğinde, TIMSS verileri kullanılarak seçilen bazı ülkelerle öğretim programlarının ve öğretmen niteliklerinin karşılaştırmalı olarak durumunu inceleyen çalışmalar (Aslan, 2005; Öztürk \& Uçar, 2010), başarıyı etkileyen faktörlerin incelenmesi (Öztürk \& Uçar, 2010; Uzun, Gelbal \& Öğretmen, 2010; Uzun \& Öğretmen, 2010), sınavla ilgili ulusal değerlendirmeler (Koca \& Şen, 2002) gibi çalışmalara rastlanmaktadır. Örneğin Aslan (2005), çalışmasında TIMSS verilerine göre fen başarısı açısından farklılık gösteren Türkiye ve Singapur'un İlköğretim fen bilgisi öğretim programlarında bulunan kazanımları, öğretme-öğrenme yaşantıları ve sınama durumları açısından karşılaştırmıştır. Benzer şekilde, Öztürk \& Uçar (2010) da sınav sonuçlarını bazı değişkenler açısından Tayvan ile karşılaştırmıştır. TIMSS sınavına yönelik başarı ve başarısızlıkların nedenlerini birçok yönden sorgulayan çalışmalar bulunmaktadır. Bu çalışmada da öğrencilerin katıldığı uluslararası sınavlarda dolaylı olarak önemli rol sahibi öğretmenlerin TIMSS sınavına yönelik görüşleri incelenmiştir.

TIMSS sınavı Türkiye'nin de aralarında yer aldığı birçok ülkenin katıldığı, dört yıllık periyotlar halinde yapılan uluslararası ölçme ve değerlendirmeyi temel alan bir sınavdır. Bu sınav sorular üzerinden öğrencilerin bilgilerini, uygulamalarını ve akıl yürütme becerilerini ölçmektedir. Uluslararası alanda yapılan sınavlarda ülkemizin genellikle ortalamanın gerisinde kaldığı maalesef sıkça karşılaşılan bir sonuçtur. Uluslararası sınavlarda üst üste düşük dereceler elde edilmesi, ülkemiz açısından eğitim öğretim sisteminde bazı sorunlar olduğunu düşündürmektedir (Altun \& Akkaya, 2014). Bu sorunların ortaya konulması ve giderilmesi için sistemin önemli bir paydaşı olan öğretmenlerin görüşleri önem arz etmektedir.

Eğitim reformlarının hedeflerine ulaşması ve öğrenci başarılarının olumlu etkilenmesi öğretmenlerin sahip oldukları niteliklerle doğrudan ilişkilidir (Stronge, Ward, Tucker \& Hindman, 2007). Öğretmenlerin uluslararası sınavlarla ilgili bilgi sahibi olmaları da birçok nitelikten biri olarak değerlendirilebilir. Bundan dolayı da öğretmenlerin TIMSS hakkındaki görüşleri, bilgileri ve soru tarzları hakkında bilgi sahibi olması önemlidir. Bu çalışma ile ülkemizdeki öğretmenlerin TIMSS sınavı hakkındaki bilgilerinin ortaya konulmaya çalışılmasının literatüre katk1 sağlayacağı düşünülmektedir.

\section{Amaç}

Birçok ülkede olduğu gibi Türkiye'de de öğretmen yeterlilikleri belirlenmiştir. Milli Eğitim Bakanlığı Öğretmen Yetiştirme ve Geliştirme Genel Müdürlüğü tarafından 2017 yılında yayınlanan Öğretmenlik Mesleği Genel Yeterlikleri kitapçığında mesleki bilgi, mesleki beceri, ve tutum ve değerler alanları altında 11 yeterlik ile 65 davranış belirlenmiş̧ir. $\mathrm{Bu}$ yeterlikler arasında ölçme ve değerlendirme alanında 5 davranış bulunmakta, kişisel ve mesleki gelişim alanında bir davranışta ögretmenlerin kişisel ve mesleki yönlerden kendini geliştirmeleri, başka bir davranışta da Türkiye ve dünya gündemini takip etmeleri beklenmektedir (MEB, 2017). TIMSS sınavı geniş̧ çaplı bir ölçme ve 
değerlendirme sınavı olmasının yanında, özellikle düzenlendiği yıllarda Türkiye ve dünya gündeminde önemli yer edinmektedir. Öğretmen yeterliklerinden açıça uluslararası sınavlarla ilgili bir madde bulunmasa da, yukarıda bahsi geçen maddeler incelendiğinde öğretmenlerin TIMSS sınavı hakkında bilgi sahibi olması beklenen bir durumdur. TIMSS sınavının dolaylı olarak paydaşı olan öğretmenlerin sınav hakkındaki bilgileri, düşünceleri, Türkiye'nin dünya sıralamasındaki yeri, sınavın içeriği, sınavda hangi alanlardan sorular çıktı̆̆ı, soruların neyi ölçtüğü gibi konularda bilgileri ve sınavda Türkiye'nin başarılı olması için sundukları önerileri ve görüşleri incelemeye değer bir konudur. Bu bilgiler doğrultusunda bu araştırmanın amacı, öğretmenlerin TIMSS sınavı hakkındaki görüşlerini belirlemektir. Bu doğrultuda araştırmacılar tarafından yarı yapılandırılmış olarak hazırlanan TIMSS Testi Öğretmen Görüşme Formunda yer alan sorulara cevap aranmıştır.

\section{Yöntem}

Araştırmanın deseni, durum çalışması desenlerinden "bütüncül çoklu durum deseni" olarak belirlenmiştir. Bu bağlamda TIMSS hakkında öğretmen görüşleri Aksaray ilinde bulunan iki farklı ortaokulda araştırılmıştır. Bütüncül çoklu durum deseninde, kendi başına bütüncül olabilecek birden fazla durum söz konusudur (Yin, 2017). Bu araştırmada da her bir öğretmenle yapılan derinlemesine görüşmeler sonucunda TIMSS sinavına yönelik öğretmen görüşleri elde edilmiş ve analiz edilmiştir.

\section{Çalışma Grubu}

Çalışma grubu, "Maksimum Çeşitlilik Örneklem Seçimi”" yoluyla belirlenmiştir. Bu seçim yönteminin amacı, küçük bir örneklem grubu oluşturmak ve çalışmaya konu olan problemle ilgili olarak taraf olabilecek katılımcıların çeşitliliğini en yüksek düzeyde yansıtmaktır (Cohen \& Crabtree, 2006; Yıldırım \& Şimşek, 2016). Bu gruplar, Aksaray ilinde bulunan iki farklı ortaokulda görev yapan branş öğretmenlerine uygulanmıştır. Araştırmaya 9'u kadın, 6's1 erkek olmak üzere seçilen ortaokullarda öğretmenlik görevlerini sürdüren 15 öğretmen katılmıştır. Ayrıca, öğretmenlerden 13'ü eğitim fakültesi mezunu, 2'si ise formasyon programı mezunu olup, 8'inin hizmet süresi 6-10 yıl aralığında, 3'ünün 1-5 yıl aralığında, 3'ünün 11-15 yıl aralığında, 1 öğretmenin ise hizmet süresi 16-20 yıl aralığındadır. Öğretmenlerin tamamı, görev yaptıkları okullarda daha önce uluslararası bir sınav yapılmadığını belirtmişlerdir.

\section{Veri Toplama Araçları}

Veriler araştırmacılar tarafından hazırlanan TIMSS Testi Öğretmen Görüşme Formu kullanılarak toplanmıştır. TIMSS Testi Görüşme Formu oluşturulurken uzman görüşüne başvurulmuştur. İki bölümden oluşan görüşme formunun birinci bölümünde öğretmenlerin cinsiyetleri, kadro türleri, hizmet süreleri, branşları, en son bitirdikleri yükseköğretim programları ve hangi sınıf düzeylerine öğretim yaptıklarına ilişkin kişisel bilgiler yer almaktadır. İkinci bölümde ise TIMSS sınavına dair açık uçlu sorular yer almaktadır. Bazı sorular öğretmenin konu alanı bilgisini ölçerken bazıları ise konu hakkındaki yorumlarını öğrenmek amacıyla hazırlanmıştır. Bu araştırma için 15 öğretmen ile okullarına gidilerek görüşmeler gerçekleştirilmiştir. Steward ve Cash (1985) görüşmeyi, önceden belirlenen soru sorma ve bu soruları yanıtlama yoluyla karşılıklı ve etkileşimli iletişim süreci olarak tanımlamaktadır. Görüşmenin amacı ise bir bireyin iç dünyasına girmek ve onun bakış açısını anlamak şeklinde tanımlanmaktadır (Patton, 1987). Bu bağlamda, yapılan görüşmeler ses kayıt cihazıyla kaydedilmiş ve sonrasında kayıtlar dinlenerek yazıya dökülmüştür. Araştırmada karşılaştırmalar yapılmış, katılımcıların verdikleri cevaplar arasında uyum ve örtüşmelerin olup olmadığına bakılmıştır. Yarı yapılandırılmış görüşme formu ve katılımcıların sorulara verdikleri cevapların değerlendirilmesi yapılmış ve elde edilen bilgiler ışığında önerilerde bulunulmuştur. Katılımcıların önerileri de dikkate alınmıştır. Bilindiği gibi nitel araştırmalarda veriler nicel araştırmada olduğu gibi sayılarla ifade edilememektedir. Nitel yöntemlerle toplanan veriler üzerinde kısıtlı düzeyde sayısal analizler yapmak mümkün olsa da, nitel araştırmada asıl amaç araştırmanın problemi ile ilgili betimsel ve gerçekçi bir görüntü sunmaktır (Yıldırım \& Şimşek, 2016).

\section{Verilerin Analizi}

Verilerin analizinde TIMSS'e dair öğretmen görüşlerinin daha iyi anlaşllabilmesi için betimsel analizden yararlanılmıştır. "Betimsel analizlerin amacı, elde edilen bulguları düzenleyerek, yorumlanmış bir şekilde sunmaktır" (Flowerday \& Schraw, 2000; Yıldırım \& Şimşek, 2016). Verilerin analizi esnasında öncelikle veriler sistematik ve 
açık bir şekilde betimlenmiş, ardından açıklanarak yorumlanmıştır. Verilerin kategorilere sınıflandırılması esnasında, katılımcıların görüşme sorularına verdikleri cevaplar bazen bir, bazen ayrıştırılarak birden fazla kategoriye yerleşmiş; bazen de konuyla ilgisi olmaması nedeniyle hiçbir kategoriye yerleşememiştir.

\section{Bulgular ve Yorum}

Araştırmada elde edilen bulgular ve yorumlar bu bölümde yer almaktadır. Görüşme formunda bulunan sorulara verilen cevaplar doğrultusunda oluşturulan kategoriler ve kodlar tablolaştırılarak frekans ve yüzdeleri ile verilmiştir. Analizler sonucunda aşağıdaki 11 kategori ortaya çıkarılmıştır:

1. TIMSS'in kelime anlamı

2. TIMSS'in eğitim-öğretim süreci ile ilişkisi

3. TIMSS hakkında ne zaman ve nasıl bilgi edinildiği

4. TIMSS'in uygulanma sıklığı, kim tarafindan uygulandığı ve değerlendirildiği ve ülkemizde uygulanması

5. TIMSS'e katılan okulların ve öğrencilerin seçimi

6. Ülkemizin TIMSS'e katılma amacı

7. TIMSS sınav sonuçları

8. TIMSS sınavında başarılı olan ülkeler ve bu ülkelerin Türkiye ile karşılaştırılması

9. TIMSS sınavının içeriği

10. TIMSS başarısının bağlı olduğu etmenler

11. TIMSS sıralamasında ülkemizin başarısının artırma

\section{TIMSS'in Kelime Anlamına Yönelik Öğretmen Görüşleri}

TIMSS'in kelime anlamına yönelik görüşler frekans ve yüzde olarak Tablo 1'de sunulmaktadır.

Tablo 1. TIMSS'in kelime anlamına yönelik öğretmen görüşleri

\begin{tabular}{lc}
\hline Görüşler & $N$ \\
\hline Uluslararası bir sınavdır. & 8 \\
\hline $\begin{array}{l}\text { Bir kısaltmadır. İngilizce açılımını tam olarak bilmiyorum. Uluslararası alanda yapılan fen ve matematik } \\
\text { sinavıdır. }\end{array}$ & 4 \\
\hline Bu kelimenin ne anlama geldiğini bilmiyorum. & 2 \\
\hline Araştırma sürecidir. & 1 \\
\hline Fen bilimleri ve matematik alanında öğrencilerin düzeyinin ölçülmesidir. & 1 \\
\hline Fen ve Matematik eğilimlerinin ülkeler arasında ne durumda olduğunun ortaya konmasıdır. & 1 \\
\hline Eğitim sistemlerinin işleyişini daha iyi anlamak için uygulanan çalışmadır. & 1 \\
\hline Öğrenci başarısını ölçmedir. & 1 \\
\hline
\end{tabular}

Tablo 1'de incelendiğinde araştırmaya katılan öğretmenler tarafindan en sık vurgulanan görüşün TIMSS'in uluslararası bir sınav olduğu $(N=8)$ görülmektedir. Ayrıca bazı öğretmenler TIMSS kelimesinin bir kısaltma olduğunu, fen ve matematikle ilgili uluslararası bir sınavı belirttiğini ifade etmişlerdir $(N=4)$. $\ddot{O}_{7}$ bu konuda "TIMSS dendiğinde aklıma matematik ve fen bilimleri dallarından yapılan kapsamlı bir araştırma geliyor" diyerek görüş belirtmiştir. Ayrıca diğer görüşler incelendiğinde bazı öğretmenlerin TIMSS kelimesinin ne anlama geldiğini bilmedikleri görülmektedir $(N=2)$. Bu öğretmenlere yarı yapılandırılmış görüşme esnasında TIMSS'in açılımı söylenmiştir. Görüşmedeki ilk soruya yönelik cevaplardan öğretmenlerin çoğunluğunun TIMSS ile ilgili bilgi sahibi oldukları tespit edilmiştir.

\section{TIMSS'in Eğitim-Öğretim Süreci ile İlişkisine Yönelik Öğretmen Görüşleri}

Tablo 2'de TIMSS'in eğitim-öğretim süreci ile ilişkisine yönelik öğretmen görüşleri frekans ve yüzde olarak paylaşılmaktadır.

Tablo 2'de katılımcıların TIMSS'in eğitim-öğretim süreci ile ilişkisine yönelik görüşleri yer almaktadır. Araştırmaya katılan öğretmenlerin çoğu TIMSS'in kaliteli eğitim için değerlendirme sınavı olduğunu $(N=4)$ ve ülkemizin hangi düzeyde olduğunu öğrenmemize yardımcı bir sınav olduğunu $(N=4)$ belirtmişlerdir. Bu tabloda yer alan görüşler incelendiğinde, katılımcıların TIMSS ile eğitim-öğretim süreci arasında bağlantı kurabildikleri anlaşılmaktadır. 
Tablo 2. TIMSS'in eğitim-öğretim süreci ile ilişkisine yönelik öğretmen görüşleri

\begin{tabular}{lc}
\hline Görüşler & $N$ \\
\hline Daha kaliteli eğitim için bir değerlendirme sınavı diye düşünüyorum. & 4 \\
\hline Eğitimde ülkemizin hangi düzeyde olduğuna dair bilgi edinmemize yardımcı olduğunu düşünüyorum. & 4 \\
\hline Ülkelerin aynı yaştaki öğrencileri değerlendirdiği bir sınavdır. & 2 \\
\hline Eğitim-öğretimin araştırma süzgecidir. & 1 \\
\hline $\begin{array}{l}\text { Öğrencilerin kazanımları ne kadar aldıkları derslerine ne kadar çalıştıkları ve bizim neleri verdiğimizi } \\
\text { ifade etmektir. }\end{array}$ & 1 \\
\hline Yaşam temelli eğitim-öğretimi ifade etmektedir. & 1 \\
\hline Matematik ve Fen alanında başarı ya da başarısızlıkları yıllara göre takip etmektir. & 1 \\
\hline
\end{tabular}

\section{TIMSS Hakkında Ne Zaman ve Nasıl Bilgi Edindiklerine Yönelik Gerekçeleriyle Öğretmen Görüşleri}

Öğretmenlerin TIMSS hakkında ne zaman ve nasıl bilgi edindikleri sorusuna verdikleri yanıtlar Tablo 3'te gerekçeleriyle birlikte frekans ve yüzde olarak verilmektedir.

Tablo 3. TIMSS hakkında daha önce ne zaman ve nasıl bilgi edindiklerine yönelik gerekçeleriyle öğretmen görüşleri

\begin{tabular}{lc}
\hline Görüşler & $N$ \\
\hline Üniversitede öğrendim. Dünya çapında kapsamlı bir araştırma sürecidir. & 5 \\
\hline MEB'in sitesinde yayınlanan raporlardan ve hizmet içi eğitimde duymuştum. & 3 \\
\hline PISA benzeri test olduğunu biliyordum. Çevremde eğitim ile ilgili konuşmalar arasında geçti. & 3 \\
\hline Daha önce duymamıştım. & 2 \\
\hline İnternet, televizyon aracılığı ile duydum. & 2 \\
\hline
\end{tabular}

Tablo 3’te de görüldüğü üzere, öğretmenlerin TIMSS hakkında ne zaman ve nasıl bilgi edindiklerine yönelik gerekçeleriyle birlikte öğretmen görüşleri incelendiğinde birç̧ok öğretmenin TIMSS'i çeşitli kaynaklardan daha önce duyduğu görülmektedir. Bu kaynaklar arasında en belirgin olanı üniversitedir. Ayrıca TIMSS hakkında daha önceden bilgi sahibi olmadığın belirten öğretmenler de bulunmaktadır $(N=2)$. Bu öğretmenlerin yapılan görüşme ile TIMSS hakkında bilgi edindikleri ifade edilebilir.

\section{TIMSS'in Uygulanma Sıklığı, Kim Tarafından Uygulandığı ve Değerlendirildiği ve Ülkemizde Uygulanmasına Yönelik Öğretmen Görüşleri}

Tablo 4'te TIMSS'in uygulanma sıklı̆̆ı, kim tarafindan uygulandığı ve değerlendirildiği ve ülkemizde uygulanmasına yönelik öğretmen görüşleri frekans ve yüzde olarak belirtilmektedir.

Tablo 4. TIMSS'in uygulanma sıklığı, kim tarafından uygulandığı ve değerlendirildiği ve ülkemizde uygulanmasına yönelik öğretmen görüşleri

\begin{tabular}{lc}
\hline Görüşler & $N$ \\
\hline En son 2015 yılında yapıldı ve ülkemiz de bu sınav uygulanmaktadır. & 9 \\
\hline $\begin{array}{l}\text { Dört yılda bir, bazı ülkelerde belirlenen eğitim kurumları tarafından uygulanmakta ve aynı kurumlar } \\
\text { tarafından değerlendirilmektedir. }\end{array}$ & 8 \\
\hline Dört yılda bir uygulanmaktadır. Kimin uygulayıp değerlendirdiğini bilmiyorum. & 5 \\
\hline $\begin{array}{l}\text { Dört yılda bir Hollanda'da bulunan IEA adlı uluslararası bir eğitim kurumu tarafından uygulanmaktadır } \\
\text { ve değerlendirilmektedir. }\end{array}$ & 1 \\
\hline Bu konuda hiçbir fikrim yok. & 1 \\
\hline
\end{tabular}

Tablo 4 incelendiğinde öğretmenlerin önemli bir kısmı sınavın 2015 yılında ülkemizde uygulandığını ve dört yılda bir yapıldığını bildiği görülmektedir. Sınavın kaç yılda bir uygulandığını bilen ancak uygulamayı yapan ve değerlendirenler hakkında fikirleri olmayan katılımcılarla birlikte $(N=5)$, konuyla ilgili bilgi düzeyi yüksek olan ve hiç bir bilgisi olmayan birer katılımcı bulunmaktadır. Sınavın dört yılda bir uygulandığını ve ülkemizde 2015 yılında uygulandığını bilmelerine rağmen, öğretmenlerin TIMSS sınavını kimin uygulayıp değerlendirdiğini bilmedikleri görülmektedir. Milli Eğitim Bakanlığı'nın TIMSS ile ilgili internet sayfasında bu bilgilere detaylı bir şekilde 
erişilebildiği göz önünde bulundurulduğunda, bir katılımcının detaylı bilgi sahibi olması beklenenin altında bir durum olarak değerlendirilebilir.

\section{TIMSS'e Katılan Okulların ve Öğrencilerin Seçimine Yönelik Öğretmen Görüşleri}

Tablo 5'te TIMSS'e katılan okulların ve öğrencilerin seçimine yönelik öğretmen görüşleri frekans ve yüzde olarak sunulmaktadir.

Tablo 5. TIMSS’e katılan okulların ve öğrencilerin seçimine yönelik öğretmen görüşleri

\begin{tabular}{lc}
\hline Görüşler & $N$ \\
\hline Her seviye ve her kademeden uygun örneklemler seçilir & 8 \\
\hline Bu konu hakkında bir bilgim yok. & 5 \\
\hline Ülke başvuruyor. Kabul edilirse pilot okul seçiliyor ve o okuldan da öğrenciler seçilmektedir. & 1 \\
\hline IEA tarafindan ülkeyi temsil etmesi adına bütün bölgelerden rastgele seçilmektedir. & 1 \\
\hline
\end{tabular}

Tablo 5'te TIMSS'e katılan okulların ve öğrencilerin seçimine yönelik her seviye ve her kademeden uygun örneklemler seçildiğini belirten çok sayıda katılımcı bulunmaktadır $(N=8)$. Önemli sayıda katılımcı da konu ile ilgili bilgisi olmadığını belirtmiştir ( $N=5$ ) olmuştur. Bir önceki kategoride yüksek düzeyde bilgisi olduğu anlaşılan katılımcı TIMSS'e katılan okulların ve öğrencilerin IEA tarafından ülkeyi temsil etmesi adına bütün bölgelerden rastgele seçildiğini ifade etmiş, bir diğer katılımcı da ülkenin sınava başvurduğunu, kabul edilirse pilot okul ve o okuldan da öğrenciler seçildiğini ifade etmiştir $(N=1)$. Bu konudaki görüşler incelendiğinde genel olarak öğretmenlerin konu ile ilgili bilgilerinin düşük olduğu görülmektedir.

\section{Ülkemizin TIMSS'e Katılma Amacına Yönelik Öğretmen Görüşleri}

Tablo 6'da ülkemizin TIMSS'e katılma amacına yönelik öğretmen görüşleri frekans ve yüzde olarak verilmektedir.

Tablo 6. Ülkemizin TIMSS’e katılma amacına yönelik öğretmen görüşleri

\begin{tabular}{lc}
\hline Görüşler & $N$ \\
\hline Uluslararası alanda öğrencilerimizin başarı durumlarının belirlenmesidir. & 5 \\
\hline Diğer ülkelerle seviyemizi karşılaştırmak ve düzeyimizi görmektir. & 4 \\
\hline Eğitim düzeyini ölçmektir. & 2 \\
\hline Öğrencilerin Fen ve Matematik alanında kazandıkları becerileri değerlendirmektir. & 2 \\
\hline Ülkemiz eğitim sisteminin kalitesini ölçmek için katılmaktadır. & 2 \\
\hline
\end{tabular}

Tablo 6'da ülkemizin TIMSS'e katılma amacına yönelik öğretmen görüşleri incelendiğinde uluslararası alanda öğrencilerimizin başarı durumlarının belirlenmesinin $(N=5)$ ve diğer ülkelerle seviyemizi karşılaştırmanın ve düzeyimizi görmenin $(N=4)$ amaçlandığını belirten katılımcılar çoğunluktadır. Bu konuda bir öğretmen "diğer ülkeler ile eğitim açısından farklılıkları ve eksiklikleri görmek amaçlanmaktadır”' şeklinde görüş belirtmiştir. Bu tabloda yer alan görüşler incelendiğinde öğretmenlerin ülkemizin TIMSS'e katılma amacına yönelik olarak benzer cevaplar verdikleri görülmektedir. Soru, yapısı nedeniyle yorumlamaya müsait bir soru olduğundan katılımcılar benzer cevaplar verebilmişlerdir.

\section{TIMSS Sınavının Sonuçlarına Yönelik Öğretmen Görüşleri}

Tablo 7'de TIMSS sınavının sonuçlarına yönelik öğretmen görüşleri frekans ve yüzde olarak sunulmaktadır.

Tablo 7. TIMSS sınavının sonuçlarına yönelik öğretmen görüşleri

\begin{tabular}{lc}
\hline Görüşler & $N$ \\
\hline Ülkemiz genel ortalamanın altında kalmışır. & 10 \\
\hline 2011 yılına göre daha başarılıyız. & 6 \\
\hline TIMSS sonuçlarını bilmiyorum. & 4 \\
\hline $\begin{array}{l}\text { Bu testte ilk sırada yer alan ülkelerin fen ve matematik bilgisi kazandırma becerileri üst düzeyde } \\
\text { diyebilirim. }\end{array}$ & 2 \\
\hline Dünya çapında bir eğitim sistemine sahip değiliz ve kendimizi yenilemek adına uygulama yapmıyoruz. & 1 \\
\hline
\end{tabular}


Tablo 7'de TIMSS sınavının sonuçlarına yönelik öğretmen görüşleri incelendiğinde en sık dile getirilen görüş ülkemizin ortalama altında kaldığı görüşüdür $(N=10)$. Bir katılımcı ülkemizin 2015 sonuçlarına bakıldığında ortalamanın 2 veya 3 sıra altında kaldığını, bir diğer katılımcı da ülkemizin hep son sıralarda yer aldığını ve eğitim öğretim açısından eksikliklerimiz konusunda çalışmalar yapmamız gerektiğini belirtmiştir. 2011 yılındaki TIMSS sınavına göre 2015 yılında Türkiye'nin başarısının arttığını belirten katılımcılar da bulunmaktadır ( $N=6$ ). Bir başka katılımcı da benzetme yaparak öğrencilere balık vermeyi değil balık tutmayı öğretmemiz gerektiği şeklinde görüş belirtmiş̧tir. TIMSS sonuçları hakkında bilgisi olmayan öğretmenler de bulunmaktadır $(N=4)$. Ayrıca iki katılımcı TIMSS sınavında ilk sıralarda yer alan ülkelerin fen ve matematik düzeyi açısından ileri düzeyde olduğunu belirtmiştir. Bazı katılımcıların bu konuda fikri olmasa da öğretmenler genel olarak ülkemizin sınav sonuçlarına göre konumu hakkında yorum yapabilmektedir.

\section{TIMSS Sınavında Başarılı Olan Ülkeler ve Bu Ülkelerin Türkiye ile Karşılaştırılmasına Yönelik Öğretmen Görüşleri}

Tablo 8'de TIMSS sınavında başarılı olan ülkeler ve bu ülkelerin ile Türkiye ile karşılaştırılmasına yönelik öğretmen görüşleri frekans ve yüzde olarak belirtilmektedir.

Tablo 8. TIMSS sınavında başarılı olan ülkeler ve bu ülkelerin Türkiye ile karşılaştırılmasına yönelik öğretmen

$$
\text { görüşleri }
$$

\begin{tabular}{lc}
\hline Görüşler & $N$ \\
\hline Singapur birincidir. Bizim ezbere dayalı bir sistemimiz vardır. & 6 \\
\hline Başarılı ülkeler hakkında tam bir bilgiye sahip değilim. & 5 \\
\hline Singapur birinciydi. Fakat politikalar hakkımda bir bilgim yok. & 3 \\
\hline Finlandiya çok başarılıdır. & 2 \\
\hline Türkiye deki eğitim sistemi çok değişken, bu nedenle başarısızdır. & 2 \\
\hline
\end{tabular}

Tablo 8 incelendiğinde katılımcılar genel olarak Singapur'un birinci olduğunu belirtmişlerdir. İki katılımc1 Finlandiya'nın da çok başarılı olduğunu ifade etmiştir. Beş katılımeı TIMSS sınavında başarılı olan ülkeler hakkında bilgi sahibi olmadığını belirtmiştir. Bir katılımcı başarılı ülkelere tamamen uzak eğitim sistemlerine sahip olduğumuzu, eğitim sistemimizin onların tersine uygulama yerine ezbere dayalı olduğunu, bir diğer katılımcı üst sıralardaki ülkelerin eğitim sisteminde daha çok uygulama ve akıl yürütmeye dayalı olduğunu, müfredatlarının daha sade olduğunu, bizim müfredatlarımızın şişkin ve daha çok bilgi ve ezbere dayalı olduğunu ifade etmişlerdir. Singapur ve Finlandiya gibi ülkeler eğitim konusunda başarılarıyla sıkça gündeme gelen ülkeler olması nedeniyle verilen cevaplar arasında sıklıkla yer bulmaları doğal olarak değerlendirilebilir. Ayrıca ülke politikaları hakkında görüş sunmayan öğretmenlerin yeterince gündemi takip etmediklerini ve bu konuda yetersiz kaldıkları şeklinde yorum yapilabilir.

\section{TIMSS Sınavının İçeriğine Yönelik Öğretmen Görüșleri}

Tablo 9'da TIMSS sınavının içeriğine, ilişkili olduğu öğretim yaklaşımına yönelik öğretmen görüşleri yüzde ve frekans olarak paylaşılmaktadır.

Tablo 9. TIMSS sınavının içeriğine ve ilişkili olduğu öğretim yaklaşımına yönelik öğretmen görüşleri

\begin{tabular}{lc}
\hline Görüşler & $N$ \\
\hline Fen ve matematikle ilgili sorulardır. & 11 \\
\hline Yapılandırmacı yaklaşım temel alınmaktadır. & 6 \\
\hline Kaliteli bir sınavdır. & 5 \\
\hline Sinavda hangi öğretim yaklaşımının kullanıldığını bilmiyorum. & 4 \\
\hline Bilme, uygulama ve akıl yürütme tarzında sorular gelmektedir. & 3 \\
\hline Sorular yoruma dayalıdır. & 2 \\
\hline Araştırma-sorgulama yaklaşımı temel alınmaktadır. & 2 \\
\hline Kolay düzeyde günlük hayat soruları bulunmaktadır. & 1 \\
\hline Sadece bilgi değil üst düzey bilişsel beceriler de içerir. & 1 \\
\hline
\end{tabular}


Tablo 9 incelendiğinde TIMSS sınavının içeriği hakkında öğretmenler tarafından en sık dile getirilen görüş içeriğin fen ve matematik alanlarını kapsadığına yönelik görüşlerdir. Fen ve matematik alanı dışında bilme, uygulama ve akıl yürütme tarzında soruların olduğunu $(N=3)$ ve sınav sorularının yoruma dayalı olduğunu belirten öğretmenler de bulunmaktadır $(N=2)$. Ayrıca bir katılımcı sınavın içeriğine yönelik örnekler vermiş, bir diğeri de üst düzey bilişsel becerilerin ölçüldüğünü ifade etmiştir. Katılımcılardan bazıları sınavda yapılandırmacı yaklaşımı $(N=6)$ ve araştırmasorgulama temelli yaklaşım $(N=2)$ temel alındığını belirtmiş̧lerdir. Sınavın ilişkili olduğu öğretim yaklaşımı hakkında yorum yapmayan dört katılımcı, sınavı kaliteli bulduğunu ifade eden beş katılımcı bulunmaktadır. Katılımcılar ağırlıklı olarak TIMSS sınavının içeriğine yönelik fen ve matematik alanlarından sorular geldiğini ve sınavın yapılandırmacı yaklaşımı temel aldığını belirtmişlerdir. 2005'ten itibaren eğitim sistemimizin önemli bir unsuru olan yapılandırmacı yaklaşımın ve 2013'ten itibaren eğitim sistemimizde yer alan araştırma-sorgulamaya dayalı yaklaşımın cevaplar arasında yer bulması beklenen bir durumdur.

\section{TIMSS Başarısının Bağlı Olduğu Etmenlere Yönelik Öğretmen Görüşleri}

Tablo 10'da TIMSS sınavlarındaki başarının hangi etmenlere bağlı olduğuna yönelik öğretmen görüşleri frekans ve yüzde olarak sunulmaktadır.

Tablo 10. TIMSS başarısının bağlı olduğu etmenlere yönelik öğretmen görüşleri

\begin{tabular}{lc}
\hline Görüşler & $N$ \\
\hline $\begin{array}{l}\text { Öğretmen, öğrenci, okul türüne, sistem, motivasyon, politika, bölge şartları, aile gibi birçok şarta } \\
\text { bağlıdır. }\end{array}$ & 9 \\
\hline Ülkenin eğitime vermiş olduğu öneme bağlıdır. & 3 \\
\hline Eğitim sisteminin kaliteli olmasına bağlıdır. & 3 \\
\hline Öğrencinin anlama isteğine ve öğrencinin öğrendiklerini hayata geçirmesine bağlıdır. & 1 \\
\hline
\end{tabular}

Tablo 10 incelendiğinde TIMSS başarısının bağlı olduğu etmenlere yönelik olarak öğretmen, öğrenci, okul türüne, sistem, motivasyon, politika bölge şartları, aile gibi şartlara, ülkenin eğitime vermiş olduğu öneme ve eğitim sisteminin kalitesine bağlı olduğu görüşleri ön plandadır. Bir katılımcı başarının tamamen eğitim sistemine bağlı olduğunu, çünkü diğer etmenlerin zaten diğer ülkelerin okullarında da bulunduğunu belirtmiştir. Bunlar dışında, başarının öğrencinin anlama isteğine ve öğrendiklerini hayata geçirmesine bağlı olduğunu belirten bir öğretmen de bulunmaktadır.

\section{TIMSS Sıralamasında Ülkemizin Başarısının Artırmaya Yönelik Öğretmen Önerileri}

Tablo 11'de TIMSS sıralamasında ülkemizin başarısını artırmak için öğretmen önerileri frekans ve yüzde olarak verilmektedir.

Tablo 11. TIMSS sıralamasında ülkemizin başarısının artırmak için öğretmen önerileri

\begin{tabular}{lc}
\hline Görüşler & $N$ \\
\hline Eğitim politikalarının geliştirilmesi sağlanabilir. & 12 \\
\hline Bu tarz sınav soruları öğrencilere sık sık çözdürülmelidir. & 4 \\
\hline Öğrencilere öğrendiklerini uygulama fırsatı verilmelidir. & 2 \\
\hline Müfredat hafifletilmelidir. & 2 \\
\hline Sınav sistemlerimiz değişmelidir. & 2 \\
\hline
\end{tabular}

Tablo 11 incelendiğinde öğretmenler TIMSS başarısının artırılması için eğitim politikalarının geliştirilmesi önerisine ağırlık vermişlerdir. Bu cevap tam olarak bir çözüm önerisi ifade etmemektedir. Zira eğitim politikaları ve eğitim programları sıkça gündeme gelmekte ve sıkça yenilenmektedir. Bazı katılımcılar TIMSS ve benzeri sınavlarda çıkmış olan soruların öğrencilere sık sık çözdürülmesi gerektiğini ifade etmiştir $(N=4)$. Eğitim politikalarının bu yönde geliştirilmesi, ulusal sınavlarda ve okullarda bu anlayışın yaygınlaşması ülke başarısının artmasında katkı sağlayabilir. $\mathrm{Bu}$ görüşü sınav sisteminin değişmesi gerektiğini belirterek destekleyen öğretmenler de bulunmaktadır $(N=2)$. Ayrıca ikişer öğretmen de öğrencilere öğrendiklerini uygulama firsatı verilmesi ve müfredatın hafifletilmesi gibi önerilerde bulunmuşlardır. 


\section{Tartışma, Sonuç ve Öneriler}

Araştırmada genel olarak öğretmenlerin TIMSS'in ne olduğunu bildikleri, bu bilgiyi beş öğretmenin üniversitede, 8 öğretmenin de informal yollarla edindikleri tespit edilmiştir. İki öğretmen TIMSS sınavını daha önce duymamış olduklarını belirtseler de, görüşme esnasında hatırlamışlardır. Ayrıca öğretmenlerin ülkemizin TIMSS'e katıldığını, katılma amacını, genel durumunu ve başarıyı artırmak için ülkemizi üst seviyelere çıkarmak adına yaptıkları yorumlar ve öneriler önemlidir. Öğretmenler ülkemizin dünya sıralamasında ortalamanın gerisinde kaldığını ifade etmişlerdir. $\mathrm{Bu}$ ifadeler alanyazın tarafından desteklenmektedir (Altun \& Akkaya, 2014). Zira, birçok çalışma bu konuya odaklanmış, örneğin başarılı olan ülkelerin eğitim sistemleri ve öğretim programları Türkiye ile karşılaştırılılmıştır. Ayrıca alanyazın incelendiğinde başarı ve başarısızlıkları etkileyen birçok değişken olduğu söylenebilir. Bireylerde birçok farklı değişkenin fen bilimleri, matematik ve yabancı diller başta olmak üzere birçok alanda başarı ya da başarısızlığa neden olabileceğini ve bu değişkenler kontrol edilebildiğinde hedeflere ulaşmanın oldukça kolaylaşacağı düşünülmektedir (Uzun, Gelbal \& Öğretmen, 2010). Öğretmenler bu seviyenin üstüne çıkabilmek için eğitim sisteminde değişiklik yapılmasını, öğretmenlik eğitimlerine daha fazla önem verilmesi, öğretmen adaylarına teorikten çok uygulama yaptırmaları gerektiğini ifade etmişlerdir. Sonuç olarak, daha önce çalıştıkları kurumlarda TIMSS sınavı uygulanmamış olsa da, öğretmenlerin TIMSS sınavı hakkında ve ülkemizin bu sınavda sınava katılan ülkeler arasında genel ortalamanın altında olduğu bilgi sahibi oldukları belirlenmiştir.

Türkiye'de öğretmenlerin mesleki deneyimleriyle öğrencilerin başarılarının ilişkilendirildiği çalışmalar bulunmaktadır. Örneğin fen ve matematik öğretmenleriyle yapılan bir çalışmada matematik öğretmenlerinin mesleki deneyim süresi arttıkça öğrencilerin matematik başarısının bir miktar arttığı, belli bir süreden sonra tekrar düşmeye başladığ1 gözlenmiştir (Büyüköztürk, Çakan, Tan \& Atar, 2014). Aynı çalışmada fen bilimleri öğretmenlerinin mesleki deneyim süresi arttığında öğrencilerin fen bilimleri başarısının arttığı ancak bu sonucun istatistiksel olarak anlamlı olmadığı belirlenmiştir. Akyüz (2006) tarafından yapılan çalışmada ise 1999 TIMSS sınavı Türkiye matematik başarıları incelenmiş ve benzer şekilde, istatistiksel olarak anlamlı olmayan sonuçlar elde edilmiştir. Bu sonuçlar, halk arasında dile getirilen tecrübeli öğretmen daha iyidir inancının doğru olmadığını göstermektedir. Bu durum, daha önceki bölümlerde de belirtildiği gibi öğretmen niteliğinin önemini ortaya koymaktadır.

Çalışmadan elde edilen sonuçlara göre aşağıdaki öneriler sunulabilir:

Öncelikle başarılı olan ülkelerin eğitim sistemlerinin ve öğretmen niteliklerinin nasıl olduğu detaylı ve programlı bir şekilde incelenmelidir. Buna bağlı olarka ülke şartlarını da göz önünde bulundurarak eğitim politikalarımızda köklü değişikliklere gidilebilir. Bunun yanında uluslararası sınavların açıklanmış soruların, aşinalığın artırılması amacıyla öğretmenlere ve öğrencilere çözdürülmesi sağlanılabileceği gibi okullarda uygulanan sınavlar bu sorular dikkate alınarak hazırlanabilir. Geleceğin teminatı olan öğrencilerimizi yetiştiren öğretmenlerin niteliğinin artırılmasına yönelik olarak proje çalışmaları ve çalıştaylar yapılmalı, lisansüstü eğitime teşvikler sağlanmalıdır. Eğitimle ilgli atılan her türlü adımda öğretmenlerin fikirleri alınmalı, beraber çalışılmalıdır; sahadan, sınıftan uzak yapılan yenilik ya da değişimlerin kaliteye dair yansımalarının pek olmadığı geçmiş yıllarda sıklıkla tecrübe edilmiştir. Ayrıca yayınlanan ulusal raporlar incelenmeli, bu raporlara yönelik eksiklikler belirlenmeli ve giderilmelidir. TIMSS sınavı matematik ve fen bilimleri alanlarını kapsadığı için fen ve matematik ders kitapları, fen eğitiminin ve matematik eğitiminin amaçlarını destekler nitelikte hazırlanmalıdır. 


\section{Extended Summary}

\section{Introduction}

TIMSS - Trends in International Mathematics and Science Study is an international examination conducted once every four years by the International Association for the Evaluation of Educational Assessment (IEA), which is a company located in the Netherlands. TIMSS determines the students' multi-faceted knowledge and skills by incorporating the 4th and 8th-grade students in the TIMSS examinations. Schools and classes to participate in the TIMSS survey are selected randomly in each examination. The main aim is to compare the examination results of participating countries and find out science and mathematics achievement of the participating students differ by countries as well as the effectiveness of their curriculum. Each TIMSS exam helps to compare the success of the students with the previous exam results, to make comparisons between countries on various issues such as the factors determining the success of the countries, to review the educational policies of the countries and the changes in the education system, and to provide solutions to the problems related to the education of countries. TIMSS measures students' knowledge, practices and reasoning skills. It is unfortunate that Turkey is generally behind the average in TIMSS. The low degree of success in international examinations suggests that there are some problems in the education system. The opinions of the teachers, who are an important stakeholder of the system, are important for the elaboration and elimination of these problems. This issue is directly linked to the need for highly qualified teachers to successfully carry out educational reforms and to increase student achievement. In this context, the teacher quality is very important in international exams. Therefore, it is important for teachers to have knowledge about TIMSS. With this study, it is thought that the teachers' TIMSS opinions will contribute to the literature about the TIMSS exam and other international examinations.

The aim of this study is to determine the opinions of teachers about the TIMSS exam. For this purpose, answers to the questions in the TIMSS Test Teacher Interview Form are sought.

\section{Method}

The research was conducted in accordance with the holistic multi-state design among case study designs. In this respect, teachers' opinions about TIMSS were investigated in two different secondary schools in Aksaray, Turkey.

The study group was determined by Maximum Diversity Sample Selection. The aim was to create a relatively small sample and to maximize the diversity of individuals who may be directly related to the problem of this study. Participants of this study were teachers working in two different secondary schools in Aksaray. A total of 15 teachers in these secondary schools participated in the research. 9 of the participants were female and 6 were male. In addition, 13 of the teachers were graduates of the faculty of education, 2 of them were graduates of the formation programs, 8 of the teachers has served between 6-10 years, 3 of them between 1-5 years, 3 of them between 11-15 years and one of them between $16-20$ years.

TIMSS Teacher Interview Form prepared by the researchers was used to collect the data. The expert opinion was consulted during the TIMSS Test Interview Form. The interview form consisted of two parts. In the first part, personal information, (i.e., gender of the teachers, types of staff, duration of service, branches, the most recently completed higher education programs, and which class levels they teach) were gathered. In the second part, there were open-ended questions about the TIMSS exam. Some questions focused the teacher's knowledge, while others were prepared to learn their comments. For this research, 15 teachers were visited, and were interviewed.

In the analysis of the data, descriptive analysis was used to get a better understanding of the opinions of teachers about TIMSS. In the analysis, the data were described systematically and clearly, the descriptions were explained and interpreted. During the classification of the data to the categories, the answers of the participants to the interview questions cannot be placed in any category sometimes, because they were sometimes separated from one, sometimes more than one, and sometimes not related to the subject.

\section{Discussion, Conclusion, and Recommendations}

According to research, professional experience periods of teachers in Turkey of increasing students' achievement in mathematics is also increasing up to a certain point and it shows a downward trend again after a certain period of time. Also in the same research, when the science and technology achievements averages based on the professional 
experience of teachers of 8th-grade students who participated in the study in Turkey examined, science and technology teachers 'professional experience periods of increased students' science and technology achievement tend to increase. The increase in the professional experience of the teachers positively affected the average success of the schools but this effect was not statistically significant. There is also other research that reported similar results in the analysis of the TIMSS 1999 mathematics data. As a result, these findings show that the experience of teachers are not as important as it is thought. As mentioned before, teacher quality should be the main issue to discuss.

In general, it was found that teachers know what TIMSS is, mostly heard from their surroundings. In particular, Turkey's participation in TIMSS, the purpose of participation, the general situation and success in order to increase Turkey's success, participants' comments and suggestions were fruitful. Teachers are aware that Turkey is below the average in the world ranking. It can be said that this is due to a wide variety of factors. Research has shown that success is connected many factors; especially in science, mathematics and foreign languages, and other courses, and if the factors can be controlled, it will be much easier to reach the educational goals and success. Teachers stated that in order to exceed this level, changes in the education system should be made. As a result, it is concluded that teachers' knowledge of TIMSS is generally sufficient and they offer valuable suggestions for increasing the success of our country. According to the results of the study, the following suggestions can be presented:

It should be examined how education systems and teacher qualifications of the successful countries are. There may be radical changes in our education policies. In addition, questions such as TIMSS and PISA can be introduced and presented to teachers and students in order to be used more in daily educational practices. Exams can be prepared by taking these questions into consideration. The quality of the teachers who raise the assurance of the future students should be increased, in-service training should be organized, and teachers' opinions should be taken under all circumstances. In addition, published national reports should be examined and deficiencies in these reports should be identified and eliminated. Since the TIMSS exam covers mathematics and science, science and mathematics textbooks should support the objectives of science and mathematics education. 


\section{Kaynakça / References}

Aslan, F. (2005). Türkiye ve Singapur Fen Bilgisi Öğretim Programlarının TIMSSR'ye Göre Karşılaştırılması, Yüksek Lisans Tezi. Ankara: Hacettepe Üniversitesi Sosyal Bilimler Enstitüsü. Ankara.

Akyüz, G. (2006). Türkiye ve avrupa birliği ülkelerinde öğretmen ve sınıf niteliklerinin matematik başarısına etkisinin incelenmesi. İlkögretim Online, 5(2), 75-86.

Altun, M., \& Akkaya, R. (2014). Matematik öğretmenlerinin pisa matematik soruları ve ülkemiz öğrencilerinin düşük başarı düzeyleri üzerine yorumları, Hacettepe Üniversitesi Ĕ̌itim Fakültesi Dergisi, 29(1), 19-34.

Büyüköztürk, Ş., Çakan, M., Tan, Ş., Ş., \& Atar, H. Y. (2014). TIMSS 2011 ulusal matematik ve fen raporu: 8. Sinıflar. Ankara: T.C. Milli Eğitim Bakanlığı Yenilik ve Eğitim Teknolojileri Genel Müdürlügüü.

Cohen D, Crabtree B (2006) Maximum variation sampling. Qualitative research guidelines. Erişim adresi: http://www.qualres.org/HomeMaxi3803.html

Flowerday, T., \& Schraw, G. (2000). Teacher beliefs about instructional choice: A phenomenological study. Journal of educational psychology, 92(4), 634-645.

Gönen, E., Özgürlük, B., Parlak, B., Polat M., \& Yıldırım, G. (2016). TIMSS 2015 ulusal matematik ve fen ön raporu. Ankara: T.C. Millî Eğitim Bakanlığı Ölçme, Değerlendirme ve Sınav Hizmetleri Genel Müdürlüğü.

Koca, S. A. Ö., \& Şen, A. İ. (2002). 3. Uluslararası matematik ve fen bilgisi çalışması-tekrar sonuçlarının Türkiye için değerlendirilmesi. Hacettepe Üniversitesi Eğitim Fakültesi Dergisi, 23(23), 145-154.

MEB (2017). Milli Eğitim Bakanlığı Öğretmen Yetiştirme ve Geliştirme Genel Müdürlüğü Öğretmenlik Mesleği Genel Yeterlikleri. Erişim adresi: http://oygm.meb.gov.tr/www/ogretmenlik-meslegi-genelyeterlikleri/icerik/39

Öztürk, D., \& Uçar, S. (2010). TIMSS verileri kullanılarak Tayvan ve Türkiye'deki 8. sınıf öğrencilerinin fen başarısına etki eden faktörlerin belirlenmesi ve karşılaştırılması. Çukurova Üniversitesi Sosyal Bilimler Enstitüsü Dergisi, 19(3), 241-256.

Patton, M. Q. (1987). How to use qualitative methods in evaluation. Thousand Oaks, CA: Sage.

Stewart, C. J., \& Cash, W. B. (1985). Interviewing: Principles and practices (4th ed.). Dubuque, IO: Wm. C. Brown Pub.

Stronge, J. H., Ward, T. J., Tucker, P. D., \& Hindman, J. L. (2007). What is the relationship between teacher quality and student achievement? An exploratory study. Journal of Personal Evaluation, 20(3-4), 165-184.

Şişman, M., Acat, M. B., Aypay, A., \& Karadağ E. (2011). TIMSS 2007 ulusal matematik ve fen raporu. 8. sinıflar. Ankara: T.C. Milli Eğitim Bakanlığı Eğitimi Araştırma ve Geliştirme Dairesi Başkanlığı.

TIMSS (2018a). TIMSS Türkiye resmi internet sitesi. Erişim adresi: http://timss.meb.gov.tr/

TIMSS (2018b). TIMSS Türkiye resmi internet sitesi, 1999 Ulusal Rapor. Erişim adresi: http://timss.meb.gov.tr/wpcontent/uploads/timss_1999_ulusal_raporu.pdf

Uzun, B. N., Gelbal, S., \& Öğretmen, T., (2010). TIMSS-R fen başarısı ve duyuşsal özellikler arasındaki ilişkinin modellenmesi ve modelin cinsiyetler bakımından karşılaştırılması. Kastamonu Eğitim Dergisi, 18(2), 531544.

Uzun, B., \& Öğretmen, T. (2010). Fen başarısı ile ilgili bazı değişkenlerin TIMSS-R Türkiye örnekleminde cinsiyete göre ölçme değişmezliğinin değerlendirilmesi. Eğitim ve Bilim, 35(155), 26-35. 
Özcan \& Koştur

Yıldırım, A., \& Şimşek, H. (2016). Sosyal bilimlerde nitel araştırma yöntemleri (10. Baskı). Ankara: Seçkin Yayıncilik.

Yılmaz, G. K., Koparan, T., \& Hanc1, A. (2016). 8. Sınıf öğrencilerinin öğrenme stilleri ve timss matematik başarıları arasındaki ilişkinin belirlenmesi. Bayburt Üniversitesi Eğitim Fakültesi Dergisi, 11(1), 36-58.

Yin, R. K. (2017). Case study research and applications: Design and methods. Thousand Oaks, CA: Sage. 